\title{
Organometallic Ru(II) Photosensitizers Derived from $\pi$ - Expansive Cyclometalating Ligands: Surprising Theranostic PDT Effects
}

Tariq Sainuddin, Julia McCain, Mitch Pinto, Huimin Yin, Jordan Gibson, Marc Hetu, and Sherri A. McFarland*

Department of Chemistry, Acadia University, Wolfville, Nova Scotia B4P 2R6, Canada

Supporting Information

Figure S1. ${ }^{1} \mathrm{H}$ NMR (upper) and ${ }^{1} \mathrm{H}-{ }^{1} \mathrm{H}$ COSY (lower) NMR spectrum of bhq in $\mathrm{CDCl}_{3}$.....................................2

Figure S2. ${ }^{1} \mathrm{H}$ NMR (upper) and ${ }^{1} \mathrm{H}-{ }^{1} \mathrm{H}$ COSY (lower) NMR spectrum of benzo[h]quinoline-5,6-dione in

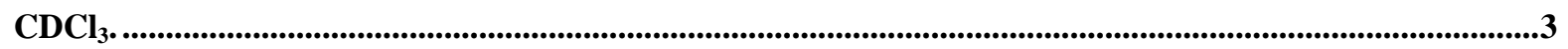

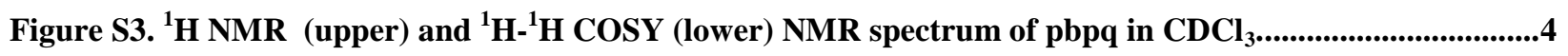

Figure S4. ${ }^{1} \mathrm{H}$ NMR (upper) and ${ }^{1} \mathrm{H}-{ }^{1} \mathrm{H}$ COSY (lower) NMR spectrum of pbpz in $\mathrm{CDCl}_{3}$.................................5

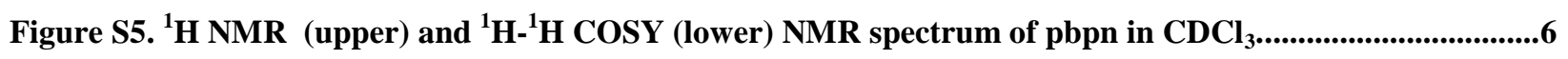

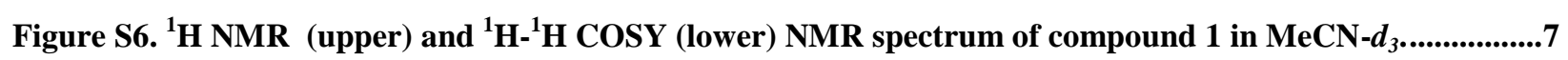

Figure S7. ${ }^{1} \mathrm{H}$ NMR (upper) and ${ }^{1} \mathrm{H}-{ }^{1} \mathrm{H}$ COSY (lower) NMR spectrum of compound 2 in MeCN- $d_{3} \ldots . . . . . . . . . . . . . .8$

Figure S8. ${ }^{13} \mathrm{C}$ NMR full spectrum (upper) and its aromatic region (lower) of compound 2 in $\mathrm{MeCN}-d_{3} \ldots . . . . . . . . .9$

Figure S9. ${ }^{1} \mathrm{H}$ NMR (upper) and ${ }^{1} \mathrm{H}-{ }^{1} \mathrm{H}$ COSY (lower) NMR spectrum of compound 3 in $\mathrm{MeCN}-d_{3} \ldots . . . . . . . . . . . . .10$

Figure S10. ${ }^{13} \mathrm{C}$ NMR full spectrum (upper) and its aromatic region (lower) of compound 3 in $\mathrm{MeCN}-d_{3} \ldots . . . .11$

Figure S11. ${ }^{1} \mathrm{H}$ NMR (upper) and ${ }^{1} \mathrm{H}-{ }^{1} \mathrm{H}$ COSY (lower) NMR spectrum of compound 4 in MeCN- $d_{3} \ldots . . . . . . . . . . .12$

Figure S12. ${ }^{13} \mathrm{C}$ NMR full spectrum (upper) and its aromatic region (lower) of compound 4 in $\mathrm{MeCN}-d_{3} \ldots . . . .13$

Figure S13. DNA photocleavage of pUC19 DNA dosed with metal complex 3 and visible light. ........................14

Figure S14. DNA photocleavage of pUC19 DNA dosed with metal complex 4 and visible light...........................15

Figure S15. Microscopic images of MC-DNA samples used for gel electrophoresis experiments.........................16 


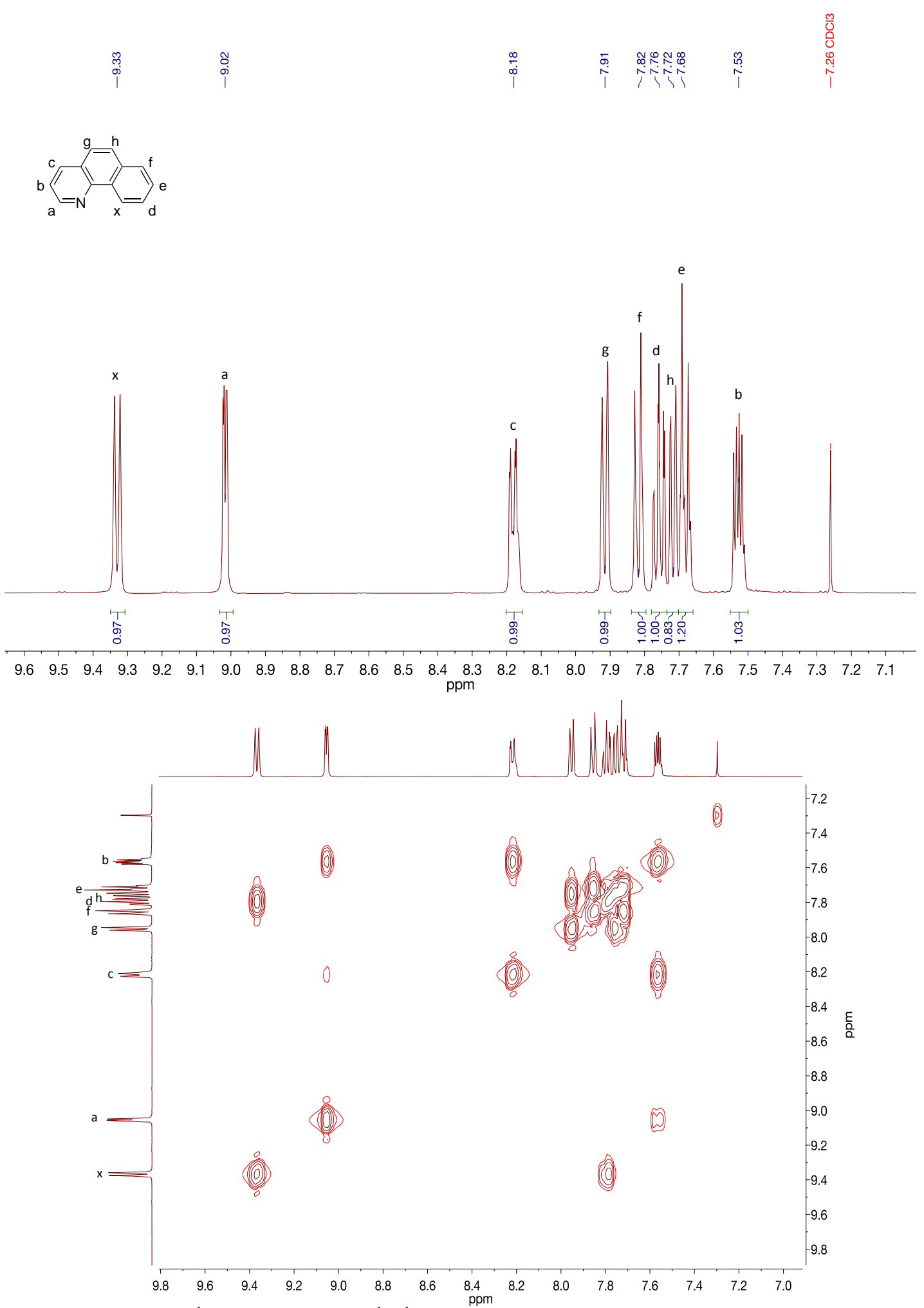

Figure S1. ${ }^{1} \mathrm{H}$ NMR (upper) and ${ }^{1} \mathrm{H}_{-}^{1} \mathrm{H}$ COSY (lower) NMR spectrum of bhq in $\mathrm{CDCl}_{3}$. 

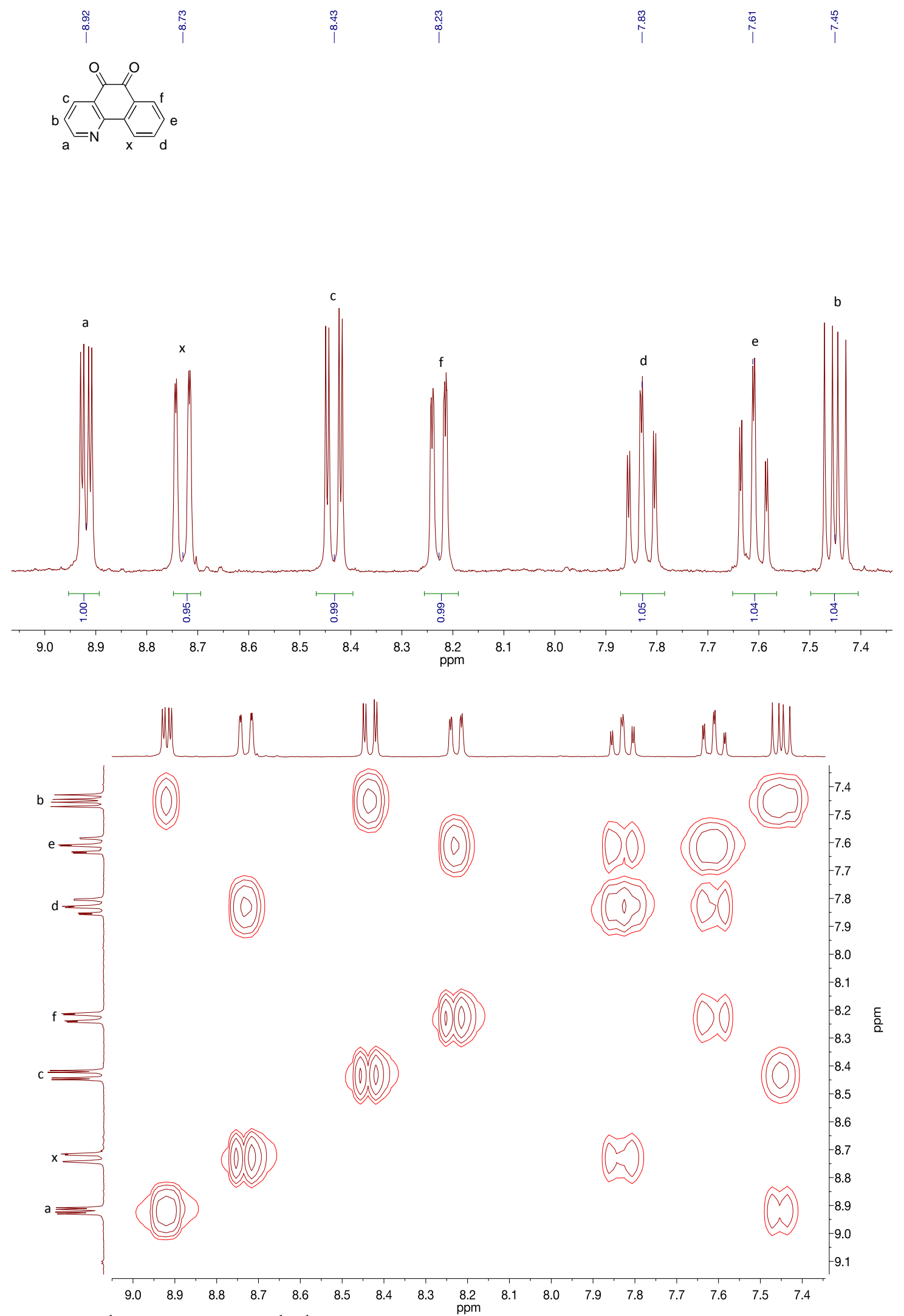

Figure S2. ${ }^{1} \mathrm{H}$ NMR (upper) and ${ }^{1} \mathrm{H}-{ }^{1} \mathrm{H}$ COSY (lower) NMR spectrum of benzo[h]quinoline-5,6-dione in $\mathrm{CDCl}_{3}$. 


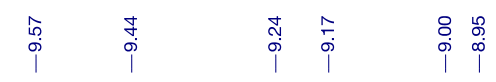
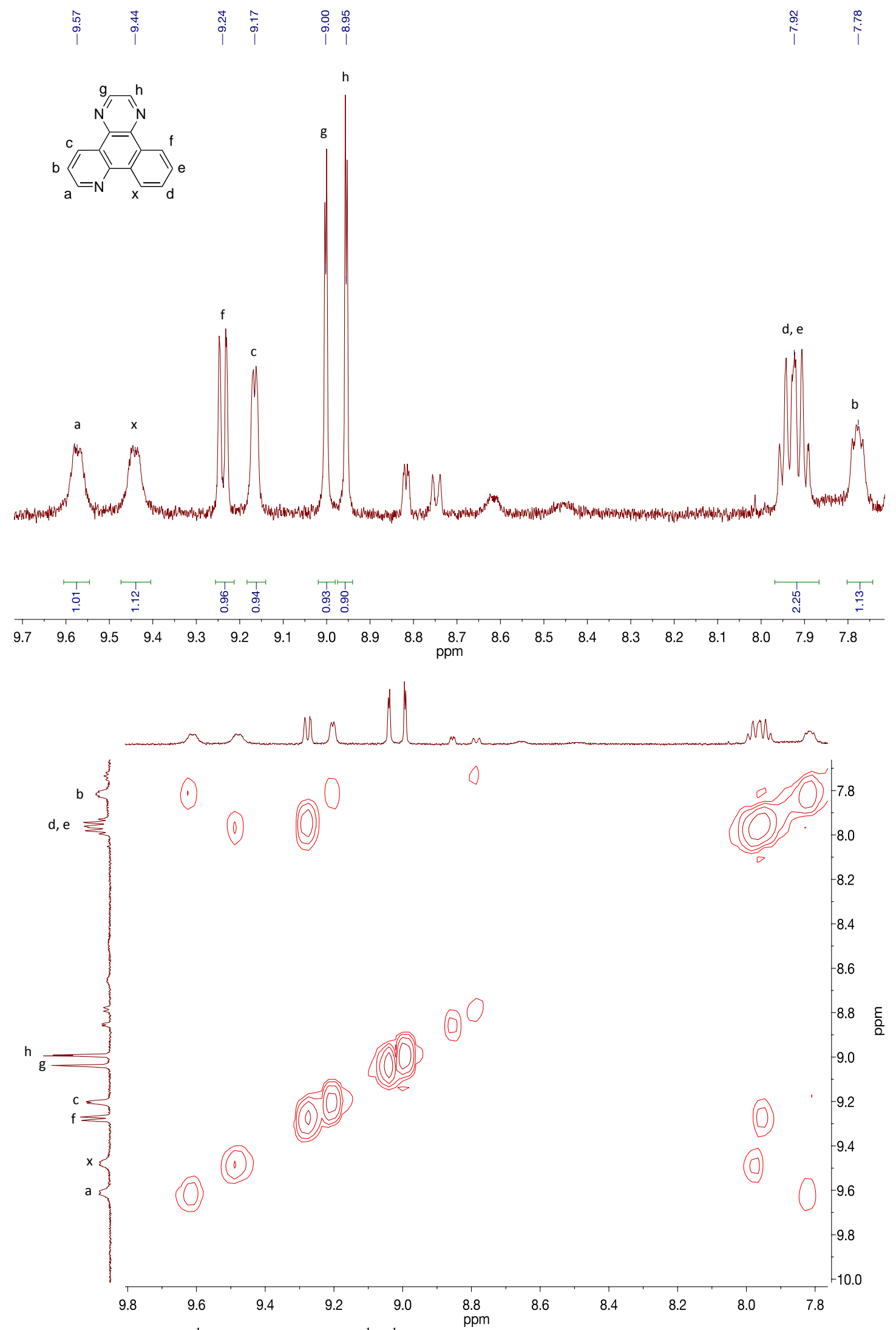

Figure S3. ${ }^{1} \mathrm{H}$ NMR (upper) and ${ }^{1} \mathrm{H}-{ }^{1} \mathrm{H}$ COSY (lower) NMR spectrum of pbpq in $\mathrm{CDCl}_{3}$. 

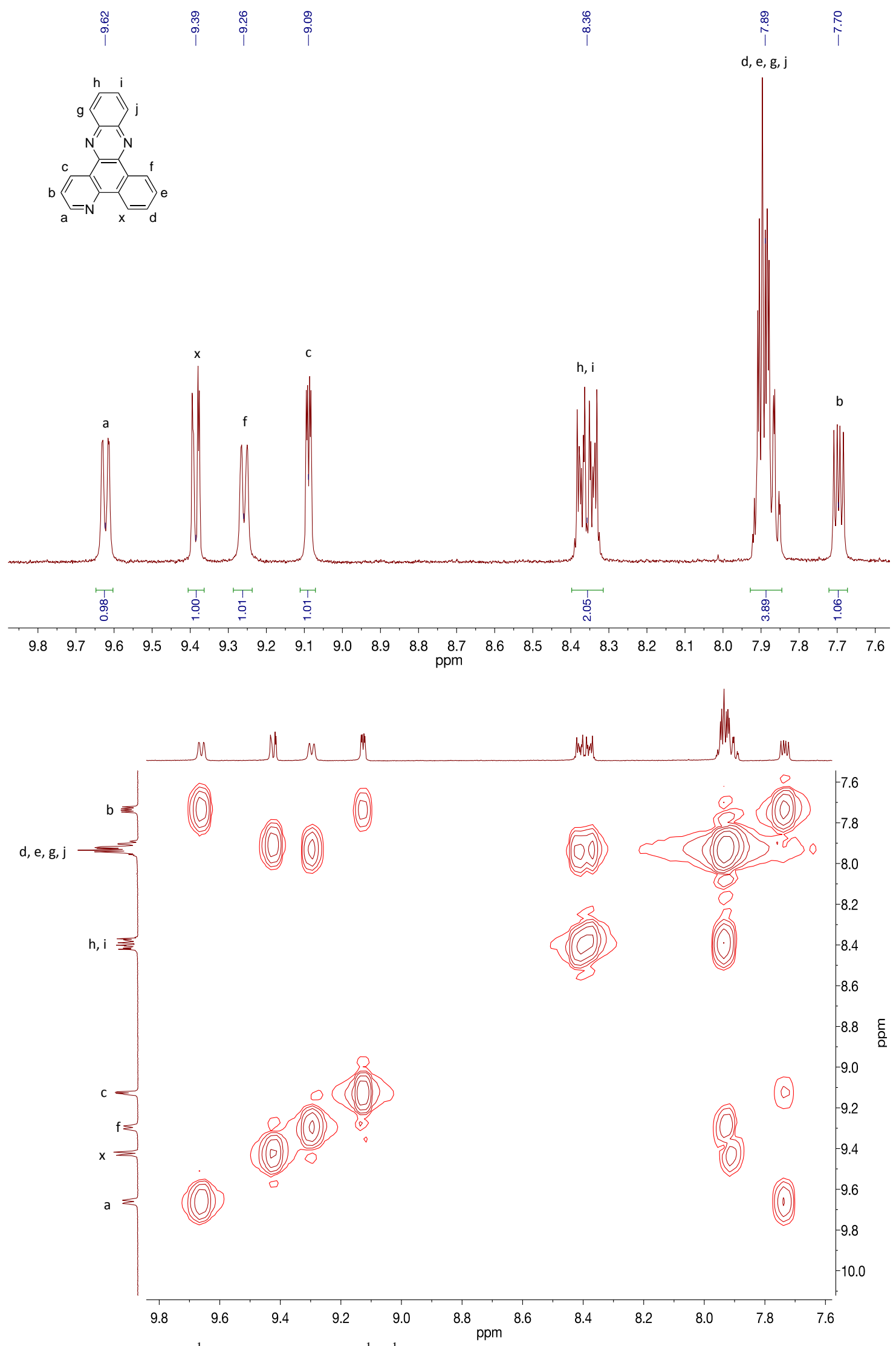

Figure S4. ${ }^{1} \mathrm{H}$ NMR (upper) and ${ }^{1} \mathrm{H}-{ }^{1} \mathrm{H}$ COSY (lower) NMR spectrum of pbpz in $\mathrm{CDCl}_{3}$. 


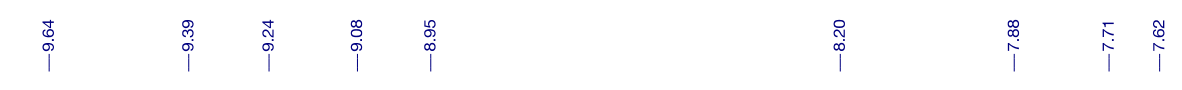
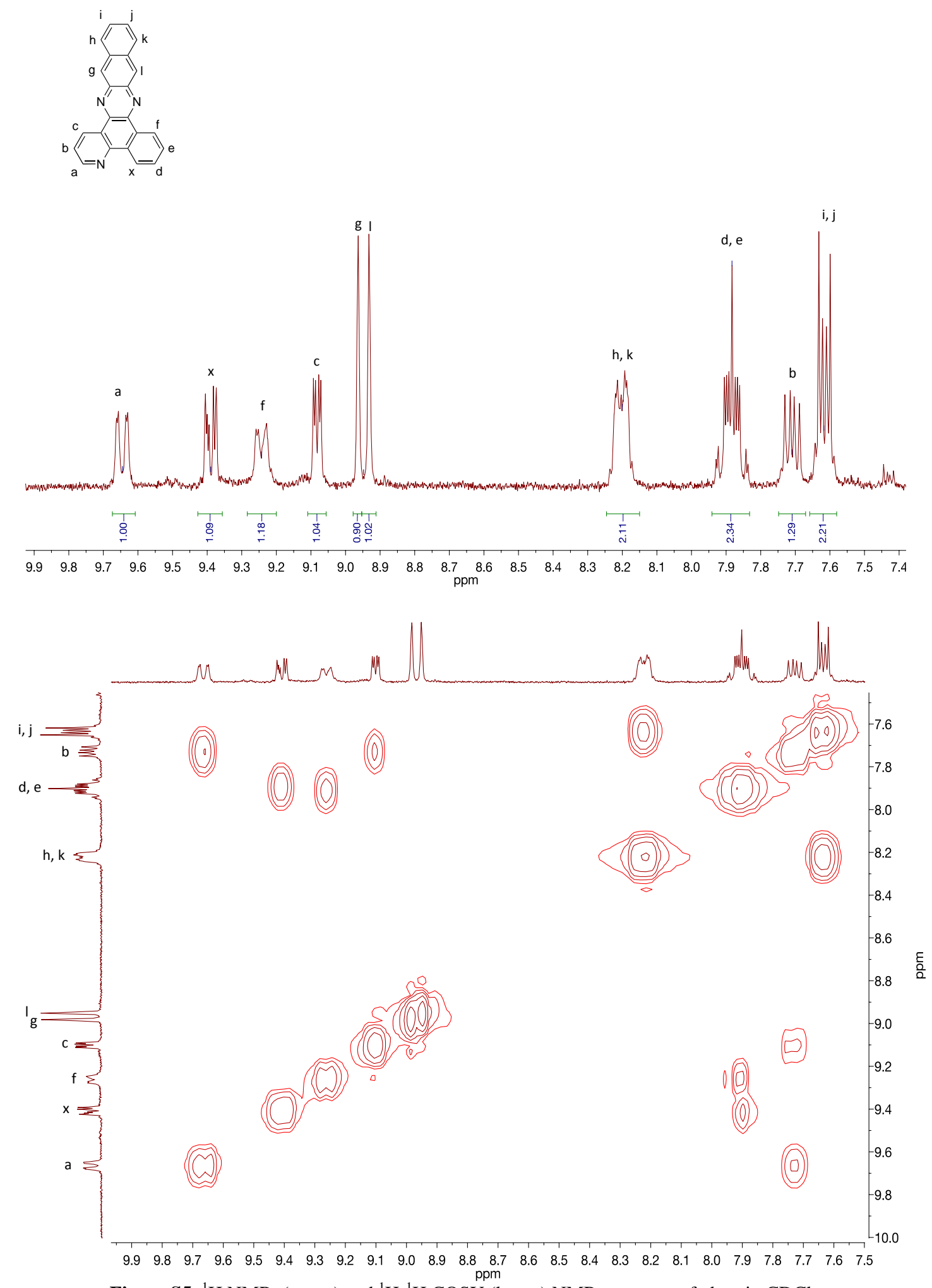

Figure S5. ${ }^{1} \mathrm{H}$ NMR (upper) and ${ }^{1} \mathrm{H}-{ }^{1} \mathrm{H}$ COSY (lower) NMR spectrum of pbpn in $\mathrm{CDCl}_{3}$. 


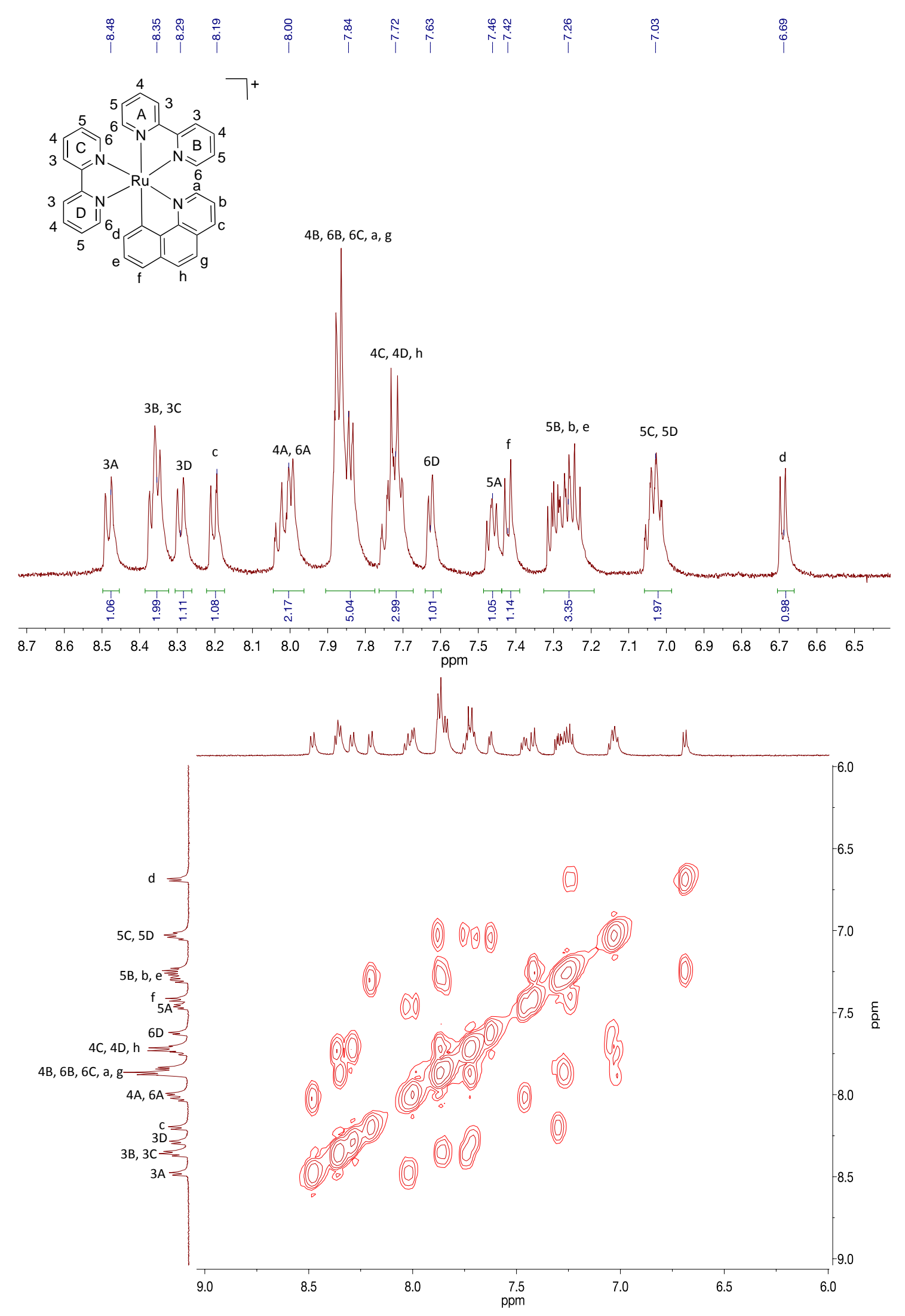

Figure S6. ${ }^{1} \mathrm{H}$ NMR (upper) and ${ }^{1} \mathrm{H}-{ }^{1} \mathrm{H}$ COSY (lower) NMR spectrum of compound $\mathbf{1}$ in $\mathrm{MeCN}-d_{3}$. 

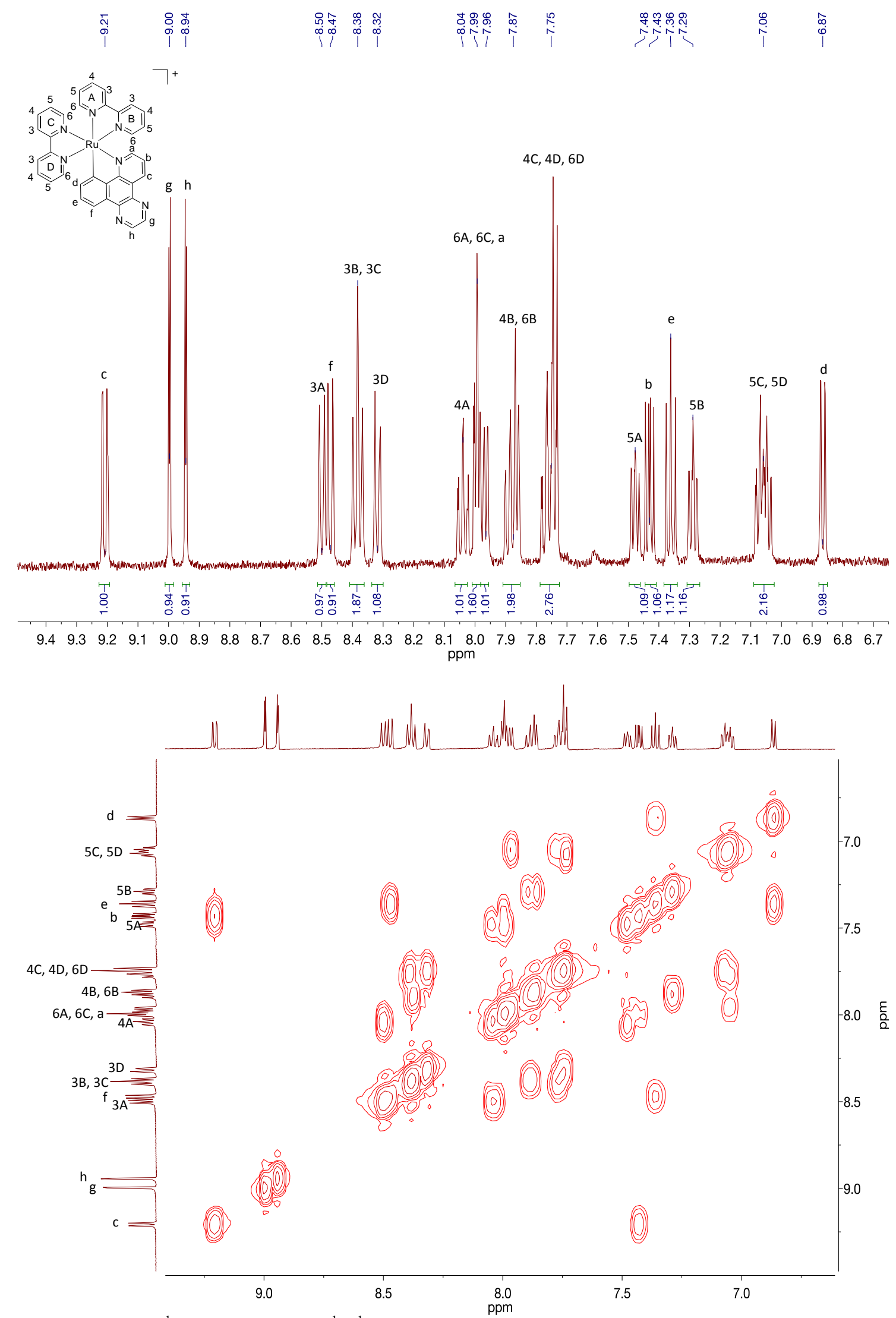

Figure S7. ${ }^{1} \mathrm{H}$ NMR (upper) and ${ }^{1} \mathrm{H}-{ }^{1} \mathrm{H}$ COSY (lower) NMR spectrum of compound 2 in $\mathrm{MeCN}-d_{3}$. 


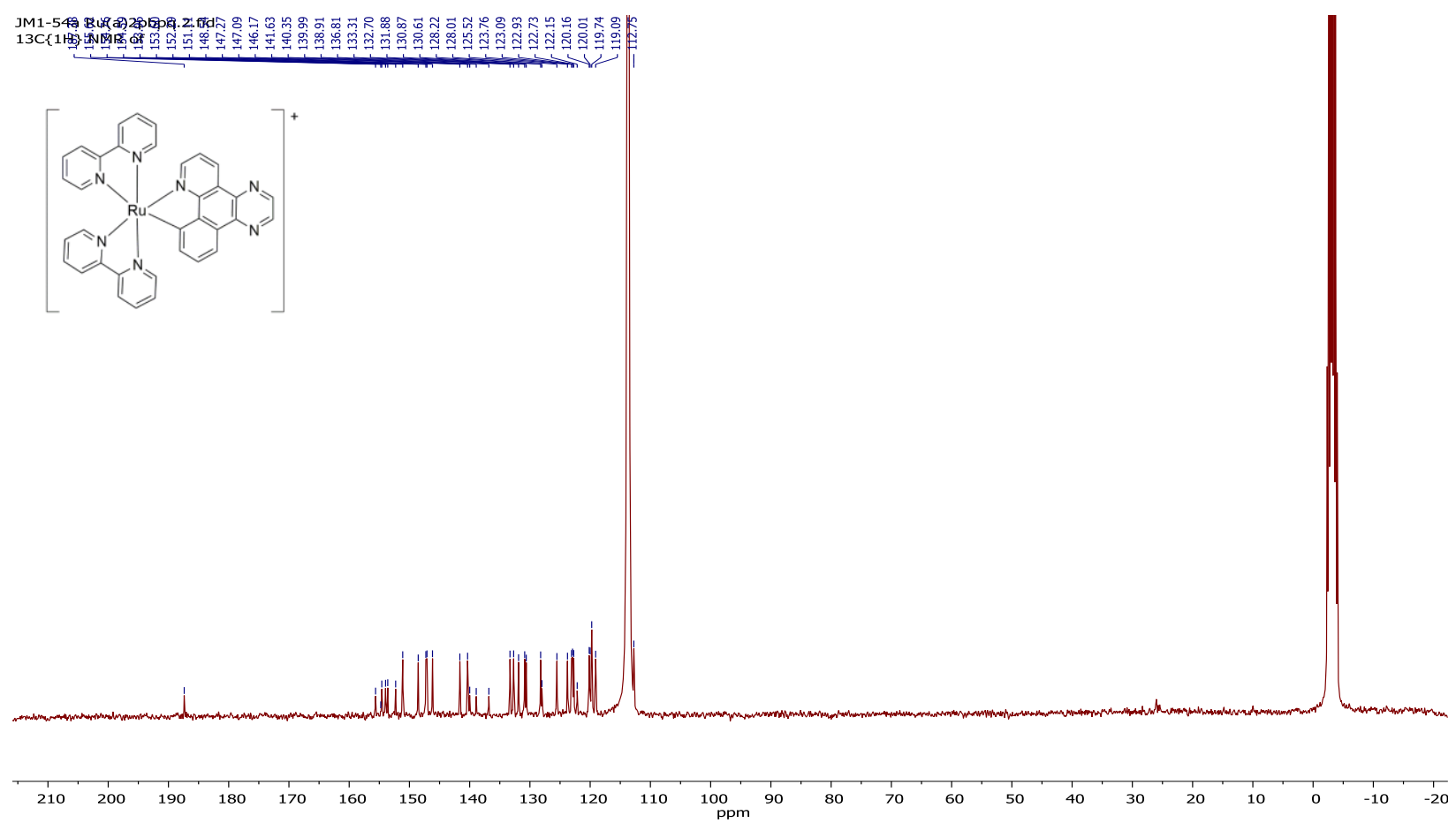

JM1-594a Ru(a)2pbpq.2.fid 13C $\{\mathrm{WH}\}$ NMR of
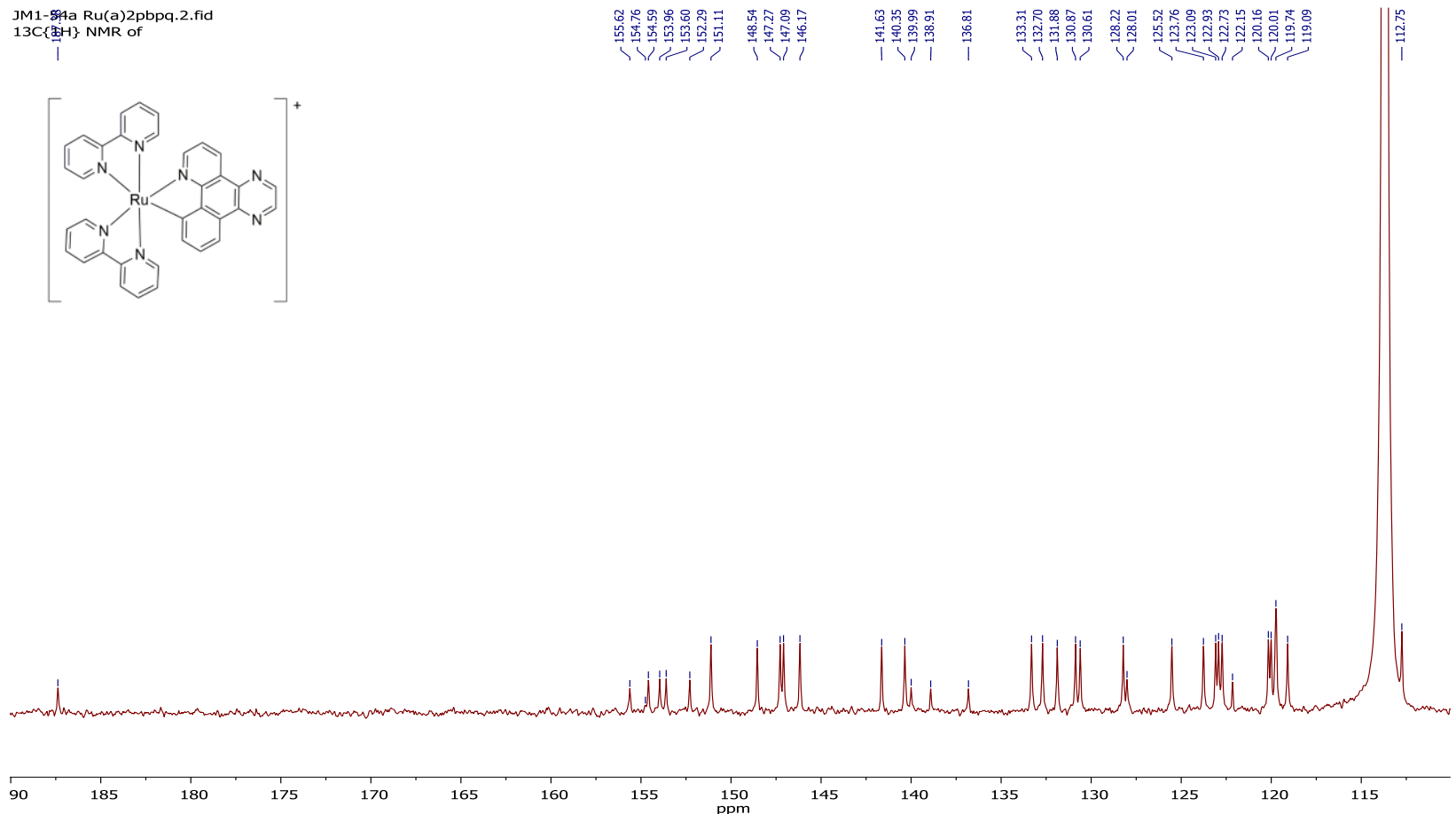

Figure S8. ${ }^{13} \mathrm{C}$ NMR full spectrum (upper) and its aromatic region (lower) of compound $\mathbf{2}$ in $\mathrm{MeCN}-d_{3}$. 


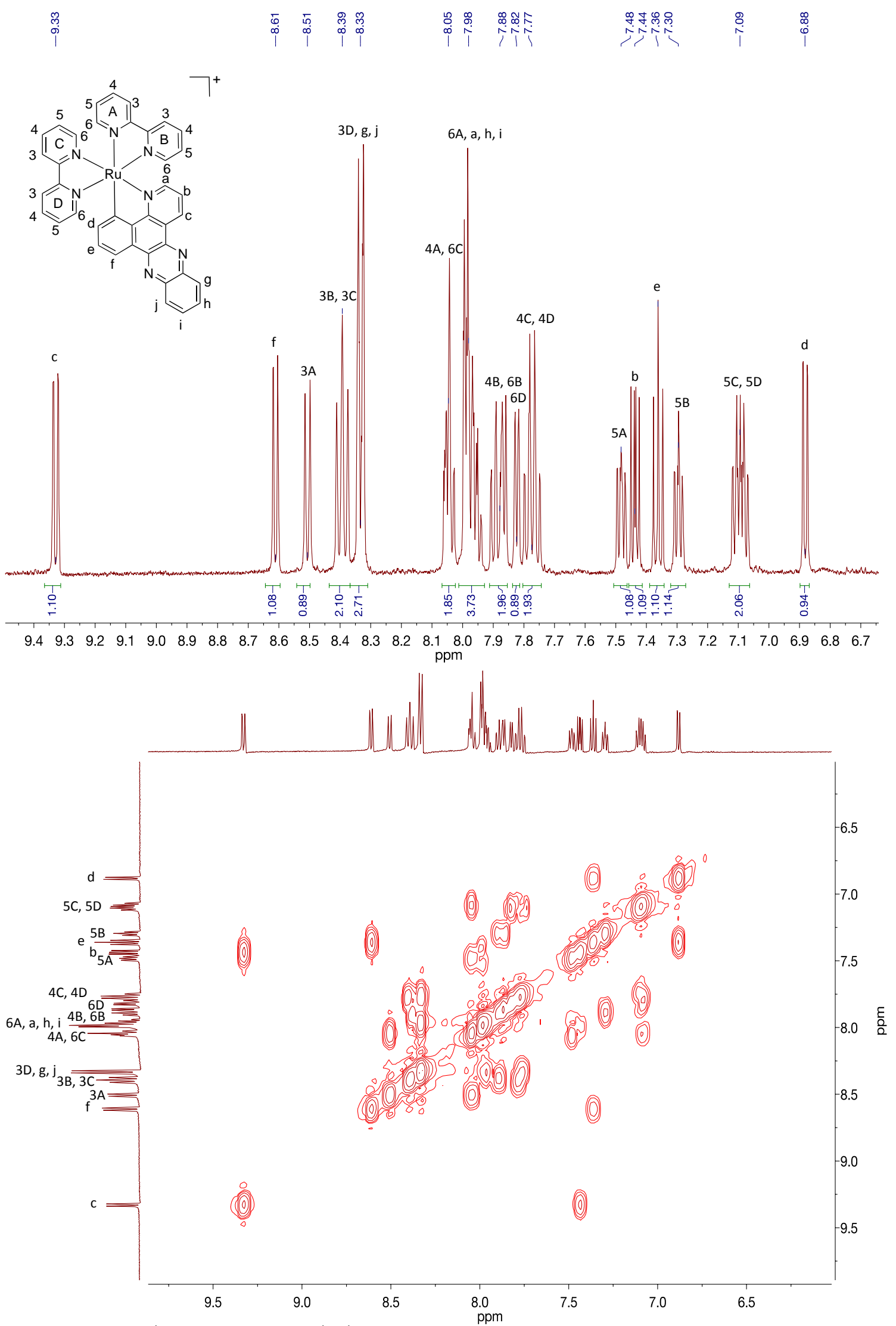

Figure S9. ${ }^{1} \mathrm{H}$ NMR (upper) and ${ }^{1} \mathrm{H}-{ }^{1} \mathrm{H}$ COSY (lower) NMR spectrum of compound $\mathbf{3}$ in $\mathrm{MeCN}-d_{3}$. 


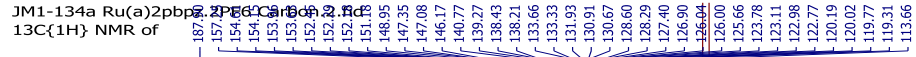
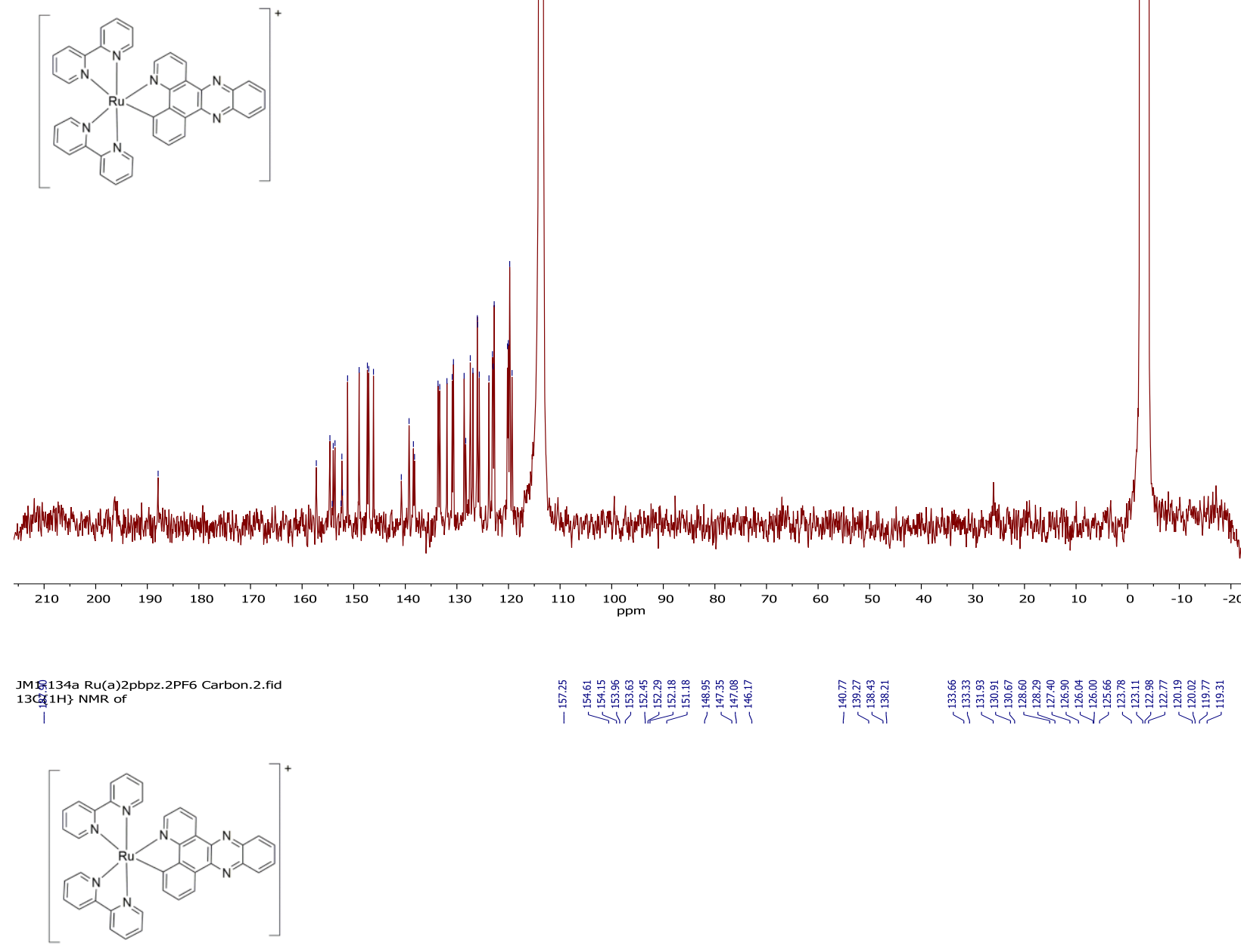

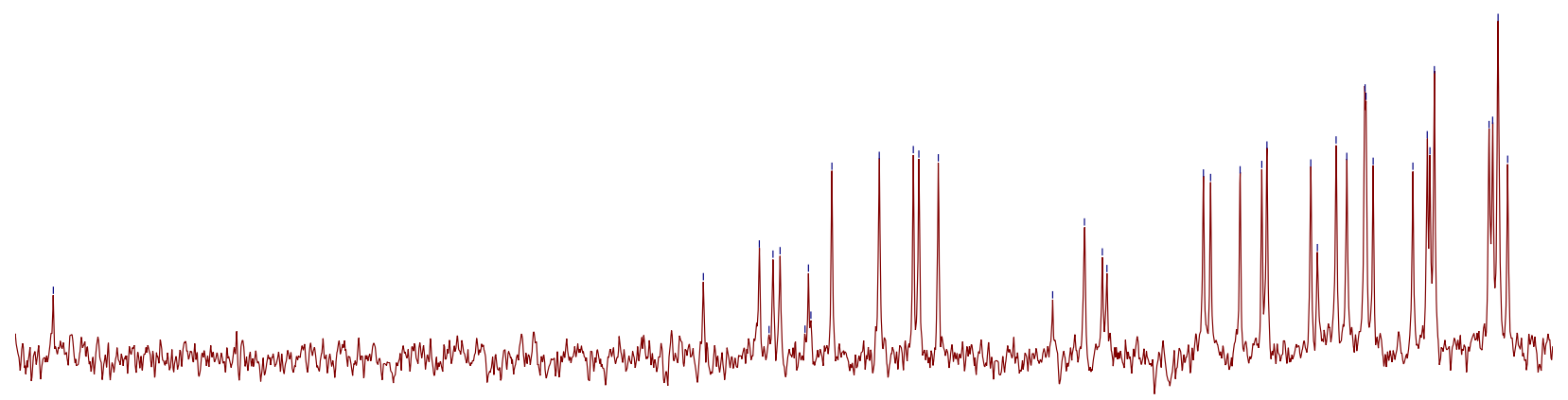

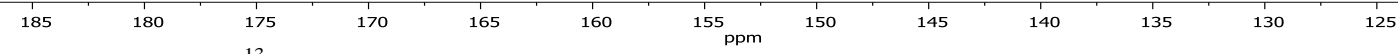

Figure S10. ${ }^{13} \mathrm{C}$ NMR full spectrum (upper) and its aromatic region (lower) of compound $\mathbf{3}$ in $\mathrm{MeCN}-d_{3}$. 


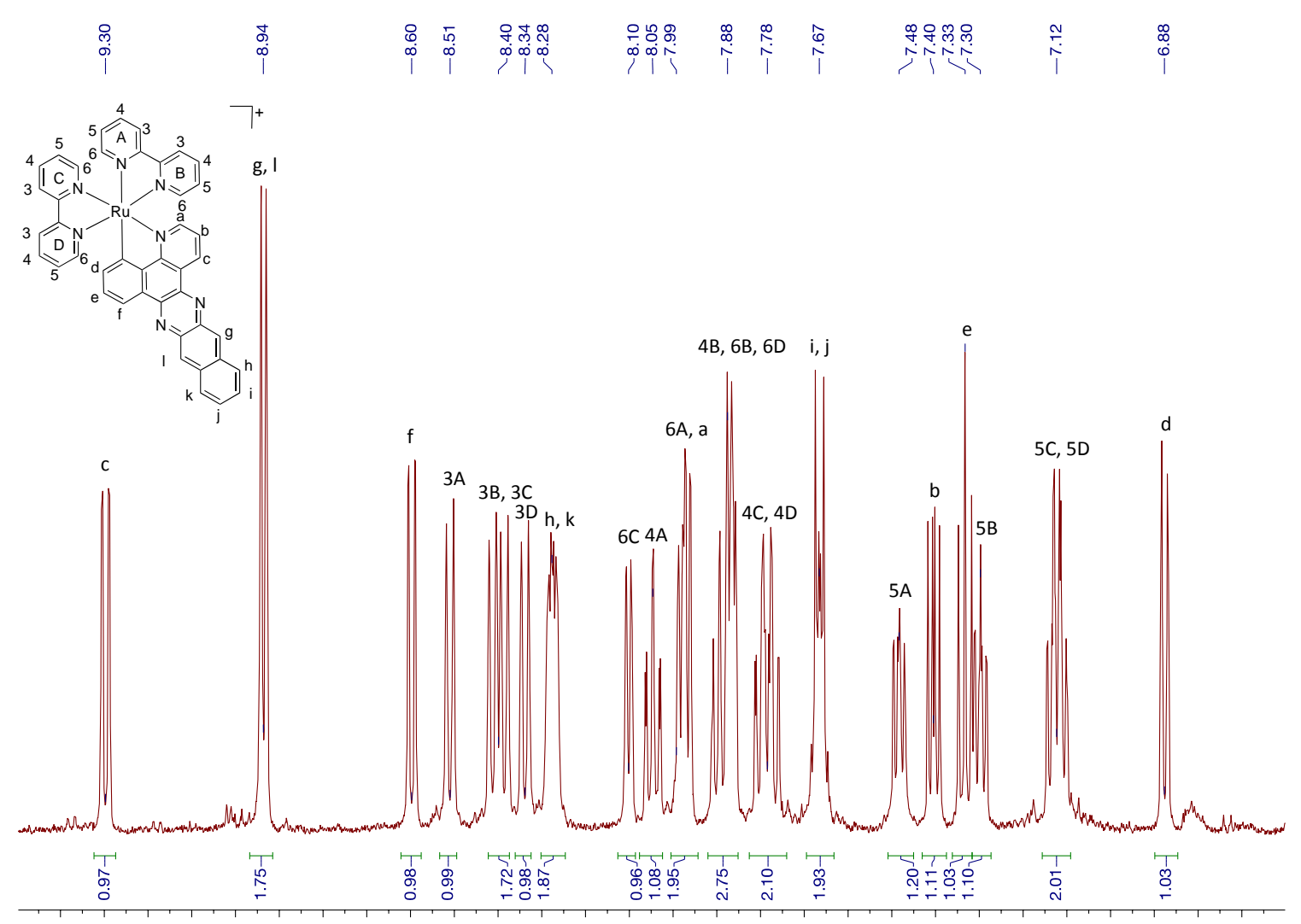

$\begin{array}{llllllllllllllllllllllllllllllll}9.4 & 9.3 & 9.2 & 9.1 & 9.0 & 8.9 & 8.8 & 8.7 & 8.6 & 8.5 & 8.4 & 8.3 & 8.2 & 8.1 & 8.0 & 7.9 & 7.8 & 7.7 & 7.6 & 7.5 & 7.4 & 7.3 & 7.2 & 7.1 & 7.0 & 6.9 & 6.8 & 6.7\end{array}$

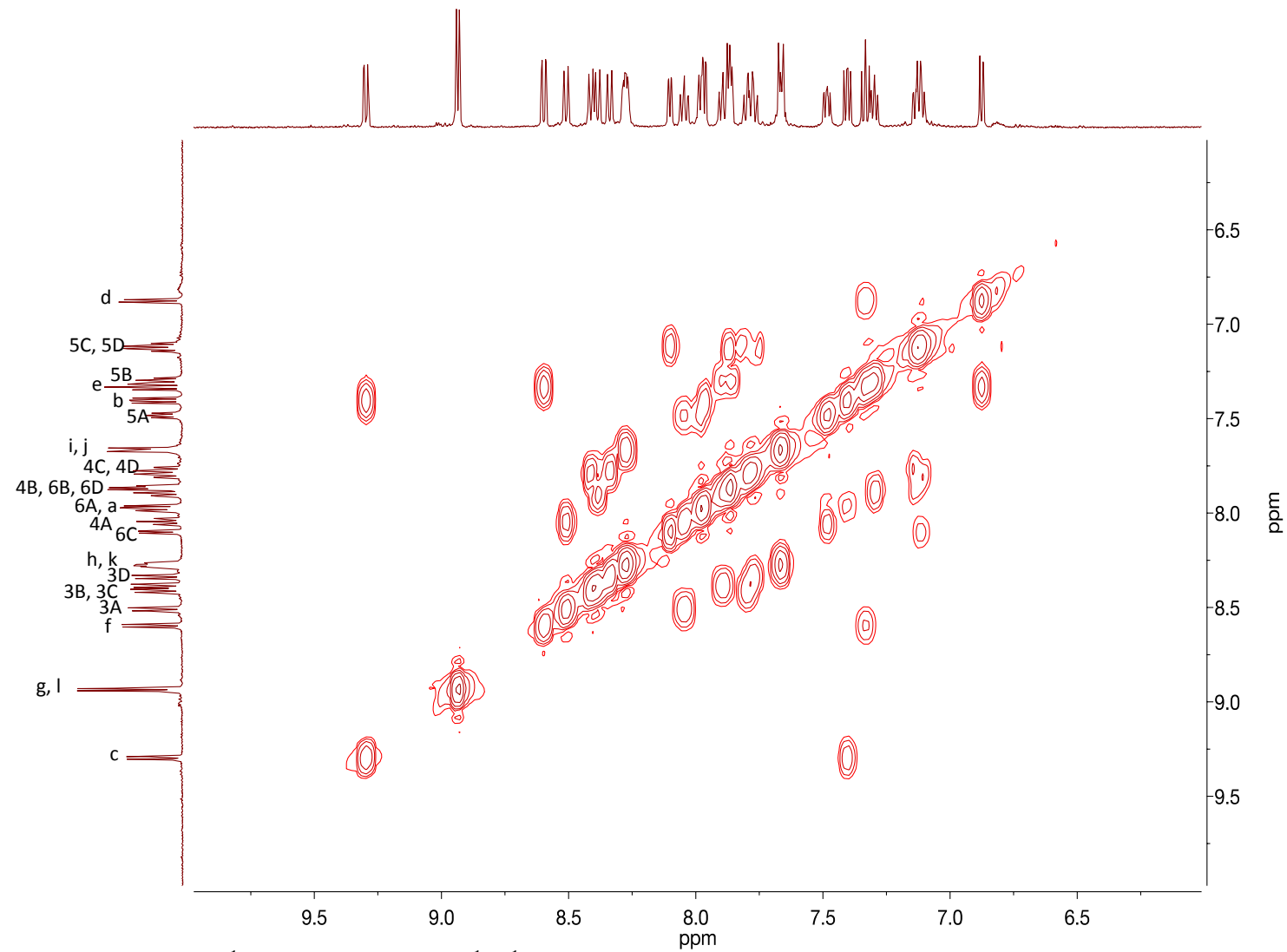

Figure S11. ${ }^{1} \mathrm{H}$ NMR (upper) and ${ }^{1} \mathrm{H}-{ }^{1} \mathrm{H}$ COSY (lower) NMR spectrum of compound 4 in $\mathrm{MeCN}-d_{3}$. 


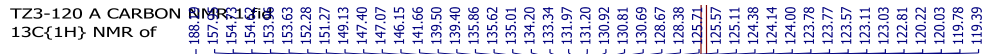

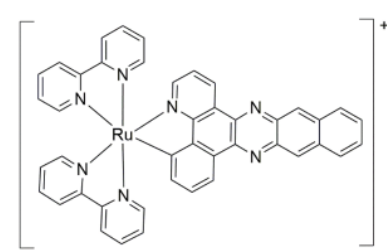

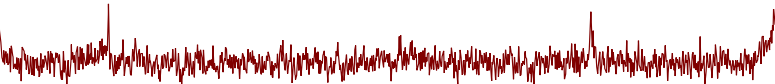

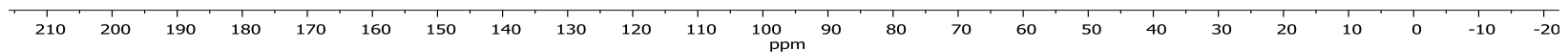

TZ3-120 A CARBON NMR.1.fid

$13 \mathrm{C}\{1 \mathrm{H}\}$ NMR $\frac{\mathrm{g}}{\mathrm{i}}$

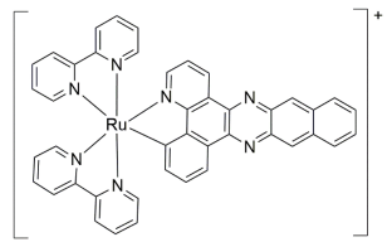

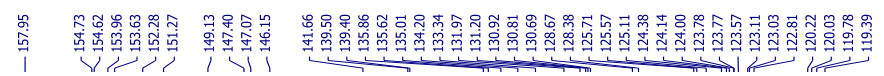

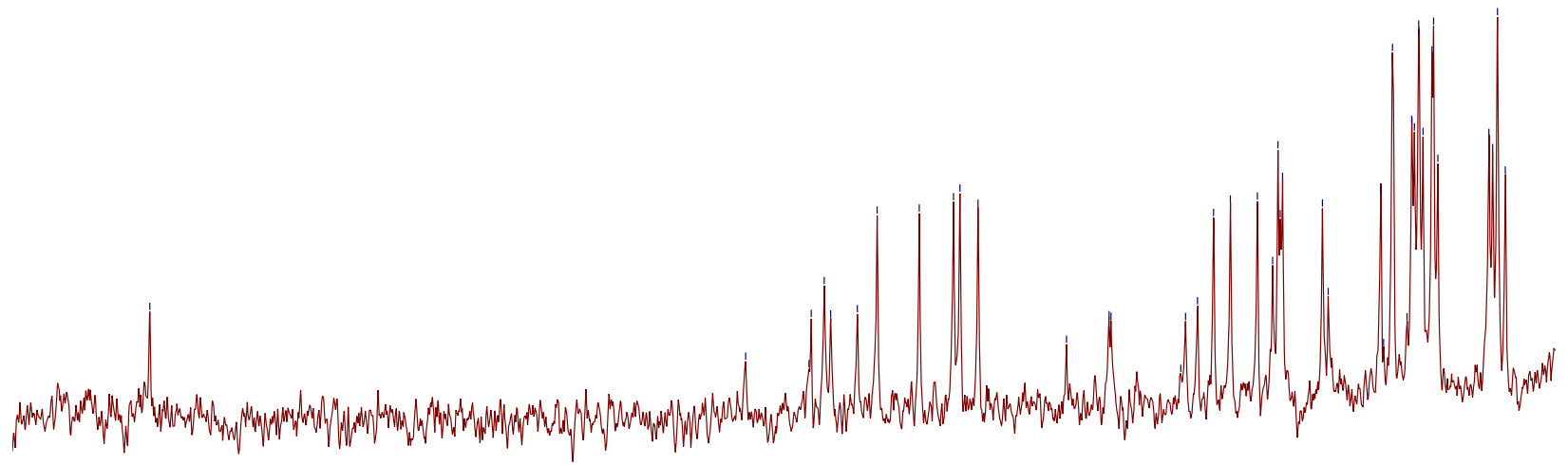$$
\text { T }
$$

Figure S12. ${ }^{13} \mathrm{C}$ NMR full spectrum (upper) and its aromatic region (lower) of compound 4 in $\mathrm{MeCN}-d_{3}$. 


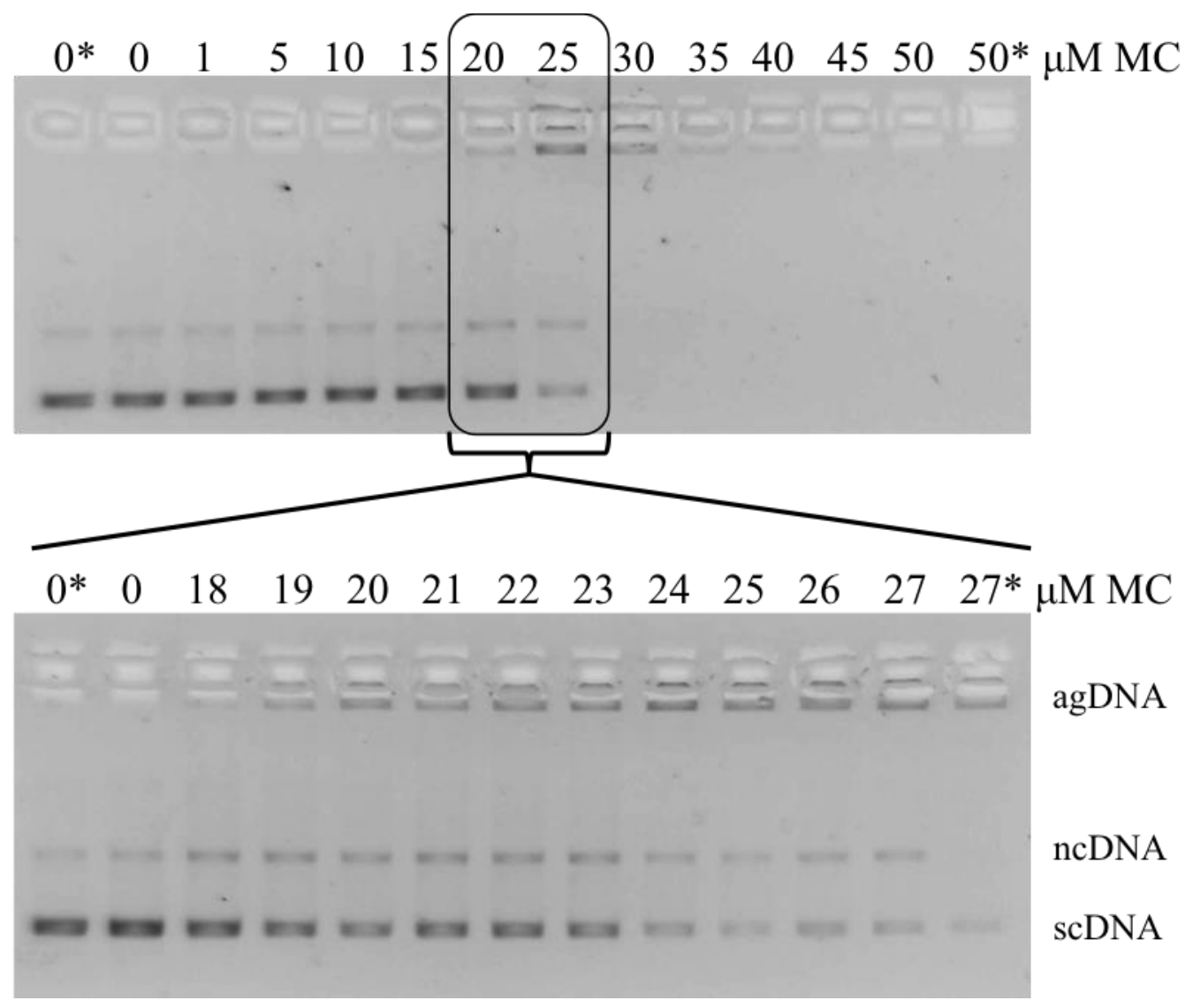

Figure S13. DNA photocleavage of pUC19 DNA (28.6 $\mu \mathrm{M}$ bases) dosed with metal complex 3 and visible light $\left(14 \mathrm{~J} \cdot \mathrm{cm}^{-2}\right)$. Gel mobility shift assays employed $1 \%$ agarose gels $\left(0.75 \mu \mathrm{g} \mathrm{mL}^{-1}\right.$ ethidium bromide) electrophoresed in $1 \mathrm{X} \mathrm{TAE} \mathrm{at} 80 \mathrm{~V} \mathrm{~cm}^{-1}$ for 30 min. *Samples not irradiated. Upper gel: 0-50 $\mu \mathrm{M} \mathrm{MC}$; lower gel: 0-27 $\mu \mathrm{M}$ MC. 


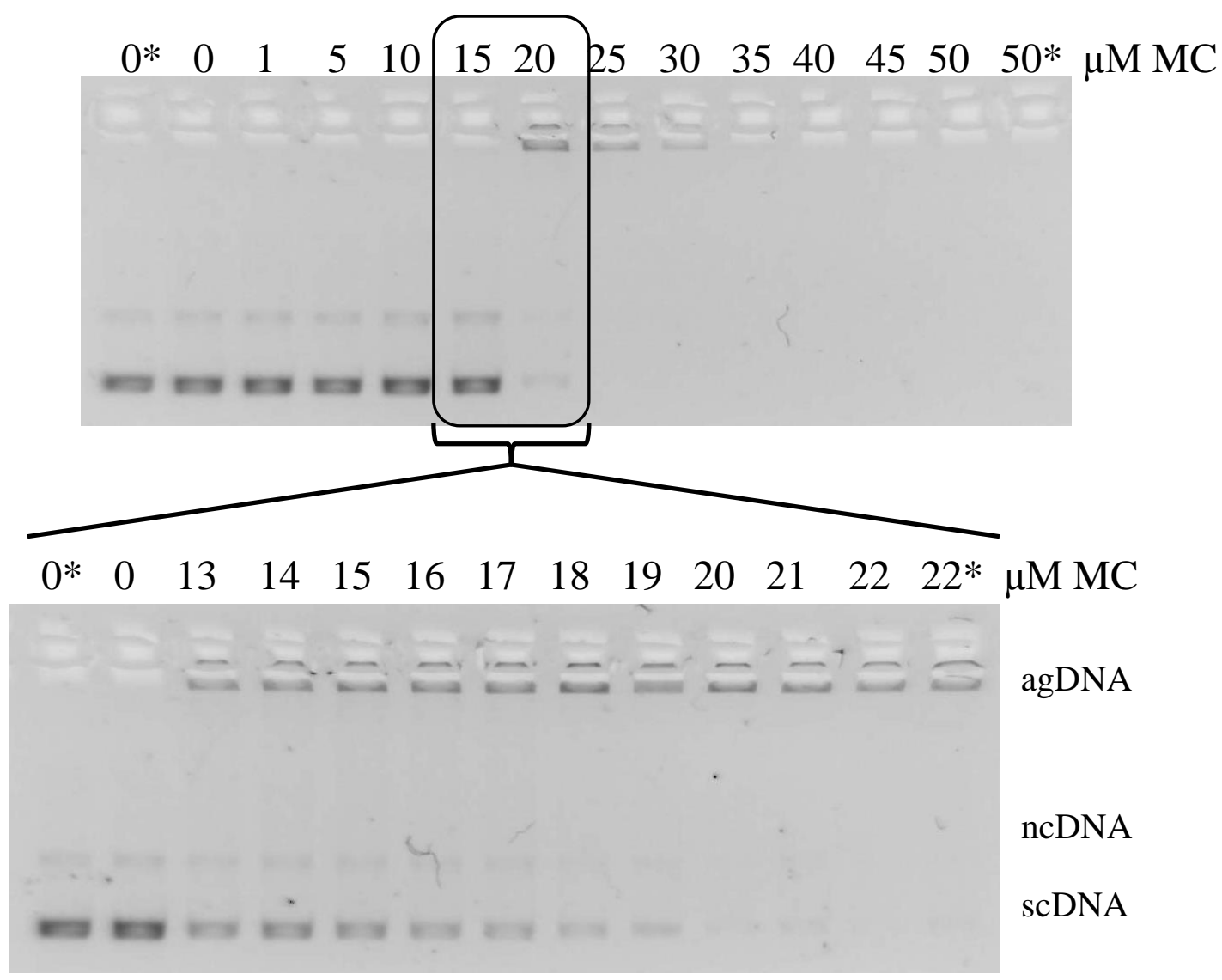

Figure S14. DNA photocleavage of pUC19 DNA $\left(28.6 \mu \mathrm{M}\right.$ bases) dosed with metal complex 4 and visible light $\left(14 \mathrm{~J} \cdot \mathrm{cm}^{-2}\right)$. Gel mobility shift assays employed $1 \%$ agarose gels $\left(0.75 \mu \mathrm{g} \mathrm{mL}^{-1}\right.$ ethidium bromide) electrophoresed in $1 \mathrm{X} \mathrm{TAE} \mathrm{at} 80 \mathrm{~V} \mathrm{~cm}^{-1}$ for 30 min. *Samples not irradiated. Upper gel: 0-50 $\mu \mathrm{M}$ MC; lower gel: 0-22 $\mu \mathrm{M}$ MC. 


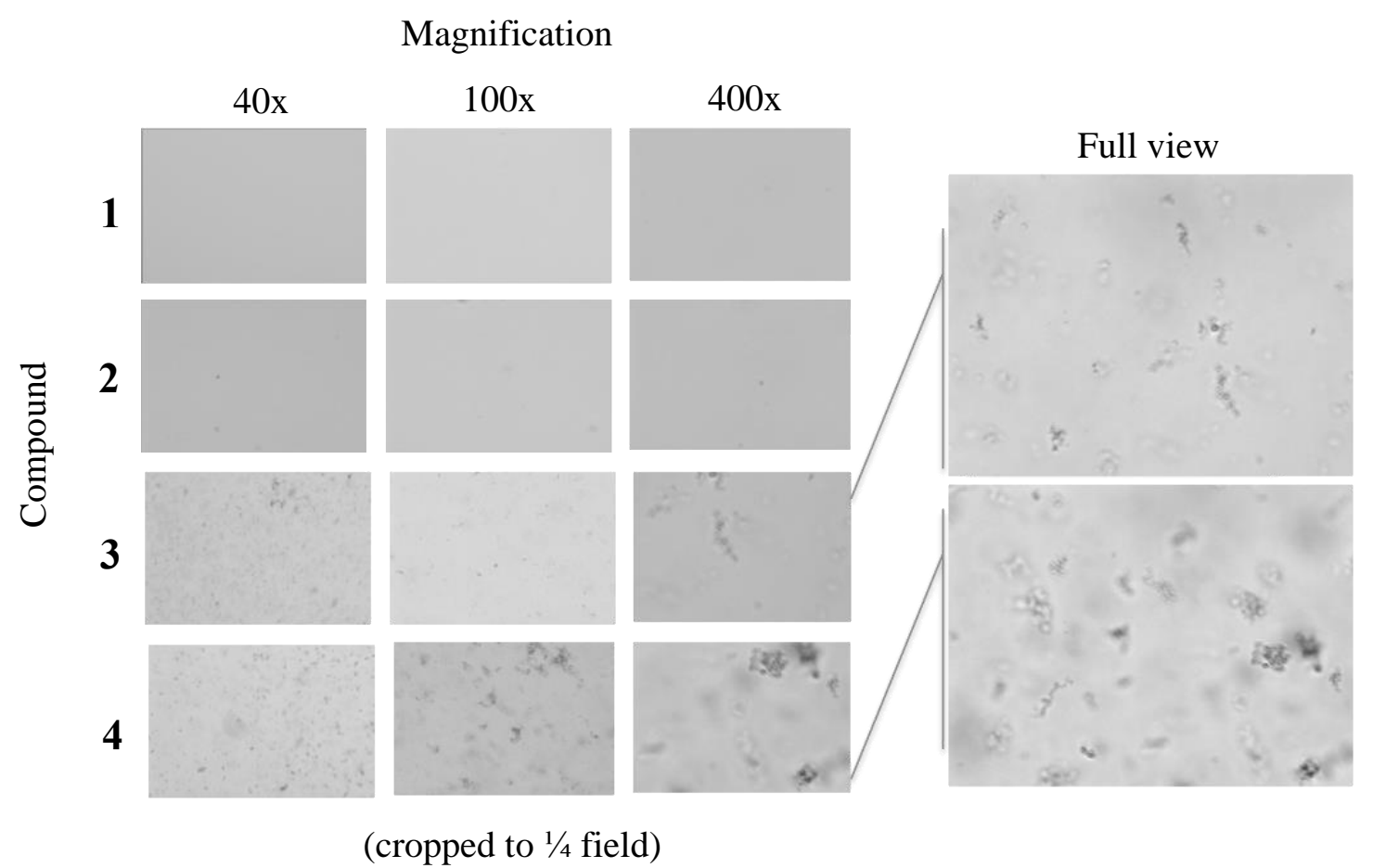

Figure S15. Microscopic images (Nikon Eclipse TE2000-U inverted light microscope, phase-contrast mode) of MC-DNA mixtures $([\mathrm{MC}]=40 \mu \mathrm{M},[\mathrm{DNA}]=28.6 \mu \mathrm{M})$ used for gel electrophoresis experiments (lane 5 in Figure 7). 